\title{
ERRATUM
}

\section{Erratum to: Neighborhood Inequalities in Adverse Pregnancy Outcomes in an Urban Setting in Spain: A Multilevel Approach}

Irene Garcia-Subirats, Glòria Pérez, Maica Rodríguez-Sanz, Dolores Ruiz-Muñoz, and Joaquín Salvador

Erratum to: Journal of Urban Health Bulletin of the New York Academy of Medicine DOI 10.1007/s11524-011-9648-4

Please note that the correct name of the fourth coauthor of this article is "Dolores Ruiz-Muñoz". That is, the coauthor's given name is "Dolores" and family name is "Ruiz-Muñoz".

Garcia-Subirats, Pérez, Rodríguez-Sanz, Ruiz-Muñoz, and Salvador are with the Agencia de Salut Pública de Barcelona, Plaça Lesseps 1, 08023, Barcelona, Spain; Garcia-Subirats, Pérez, Rodríguez-Sanz, RuizMuñoz, and Salvador are with the Centro de Investigación Biomédica en Red de Epidemiología y Salud Pública (CIBERESP), Parc de Recerca Biomèdica de Barcelona, Carrer Aiguader, $881^{\mathrm{a}}$ Planta, 08023, Barcelona, Spain; Pérez and Rodríguez-Sanz are with the Facultat de Ciencies de la Salut i de la Vida, Universitat Pompeu Fabra, Carrer Aiguader, 80 Campus Mar, 08023, Barcelona, Spain; Pérez, RodríguezSanz, Ruiz-Muñoz, and Salvador are with the Institute of Biomedical Research (IIB Sant Pau), Hospital de la Santa Creu i Sant Pau, Carrer Sant Antoni Maria Claret, 167, 08025, Barcelona, Spain.

Correspondence: Glòria Pérez, Agencia de Salut Pública de Barcelona, Plaça Lesseps 1, 08023, Barcelona, Spain. (E-mail: gperez@aspb.cat)

The online version of the original article can be found at doi:htt://dx.doi.org/10.1007/s11524-011-9648-4. 